\title{
Nausea and vomiting in pregnant adolescents: impact on health-related quality of life
}

\author{
Elif Yılmaz, Betül Tokgöz, Çağanay Soysal, Seda Şahin Aker, Tuncay Küçüközkan
}

Department of Obstetrics and Gynecology, Dr. Sami Ulus Maternity and Womens' Health Training and Research Hospital, Ankara, Turkey

DOI: $10.18621 /$ eurj.353985

\begin{abstract}
Objectives: To determine the impact of the presence and severity of nause and vomiting in pregnancy (NVP) on health-related quality of life in pregnant adolescents.

Methods: Two hundred and fifty adolescent pregnant women were included in this study. The Rhodes test was performed to determine the severity of nausea and vomiting, and the self-reported 36-Item Short Form Survey (SF-36) Scale was administered. The study was divided into four groups according to nausea severity (no, mild, moderate, severe) groups and SF-36 scores were compared among the groups.

Results: Of the 250 pregnant women included in the study, $74.5 \%$ of women reported NVP. Low scores on the SF-36 were found for all items with increasing severity of NVP, with the lowest scores in the severe NVP group and the highest scores in the group with no NVP $(p=0.001)$. Multivariable analyses showed that severity of NVP was the most important factor for both the physical (PCS) and mental component summary (MCS) scales. The number of living children was significantly associated with lower PCS scores and being unable to share problems with spouse/relatives was correlated with lower MCS scores.

Conclusion: The negative impact of nausea and vomiting on health-related quality of life, emphasises the importance of psychological support and optimal management of NVP in pregnant adolescents.
\end{abstract}

Keywords: Adolescent, pregnancy, nausea, vomiting, health-related quality of life

Received: November 15, 2017; Accepted: January 23, 2018; Published Online: March 24, 2018

$\mathrm{T}$ he definition of health has changed in recent decades. According to the World Health Organization (WHO), health is a state of complete physical, mental and social well-being [1]. This change in the idea of health has led to an increase in the importance of the quality of life (QoL) concept in recent years. When QoL is considered in the context of health and disease, it is commonly referred to as health-related quality of life (HRQoL). HRQoL is a multi-dimensional concept, that includes physical, emotional and mental perceptions and social functioning. According to the WHO, QoL is the perception of an individual of his/her own position in life in the context of the culture and value systems in which he/she lives and in relation to his/her aims, expectancies, standards and worries [1].

Although pregnancy is accepted as physiological phenomena, both physical and mental aspects of maternal health can be adversely affected during this period. Changes that occur during pregnancy can 
reduce a woman's QoL by altering her ability to carry out her usual roles in daily life $[2,3]$. As well as a reduction in physical performance, pregnant women have more limitations due to emotional problems and social functioning, which causes a decrease in their perception of level of health and well-being $[4,5]$. Another issue to be considered that can lead to a deterioration in HRQoL and that interferes with the physical and psychological condition of pregnant women, is the nausea and vomiting in pregnancy (NVP) experienced by $70-80 \%$ of all pregnant women [6-9]. In addition to the deterioration in physical health, the mental and physical stress caused by nausea and vomiting can lead to depressive feelings and promotes a significant negative influence on the family and on the social and occupational functioning of pregnant women who have NVP [8, 10]. An important point to be kept in mind is that the severity of these negative effects seems to be related to the severity of NVP [7, 10, 11]. A more severe form of NVP, hyperemesis gravidarum defined as tenacious vomiting which is associated with metabolic disturbances and more than 5\% of pre-pregnancy body weight loss. The prevelance of hyperemesis gravidarum is given as $0.3-2 \%$ and defined as the most common reason for hospitalization in first half of pregnancy $[12,13]$.

Despite the increased importance of health related quality concepts in recent years, only a few studies have focused on the association between NVP and HRQoL in pregnant women. Although a few studies show the impact of the presence or severity of NVP on HRQoL, data on the role of NVP and its severity on HRQoL in pregnant adolescents, which is one of the greatest problems especially in developing countries, are still limited [6-8]. About 16 million adolescent women give birth each year, approximately $11 \%$ of all births worldwide, with the number increasing every year, especially in low- and middleincome countries. Thus the aim of this study was to determine the impact of NVP presence and severity on HRQoL during the first 20 weeks of pregnancy in pregnant adolescents.

\section{METHODS}

A prospective cross-sectional study was conducted with adolescent pregnant women ( $\leq 19$ years) receiving routine prenatal care at the outpatient obstetric clinics of a major tertiary maternity hospital in Ankara, Turkey, from July-December 2015. The study group consisted of 250 adolescent pregnant women aged between 15-19. The inclusion criteria were having a viable singleton pregnancy $\leq 20$ weeks, absence of congenital anomalies, systemic diseases (diabetes, thyroid dysfunction, urinary-hepatobiliary and gastrointestinal disease, hematologic diseases, depressive disorders) and the exclusion criteria were maternal age $\geq 20$ years, fetal death and threatened abortion. Hiperemesis gravidarum (defined as severe vomiting resulting in dehydration and weight loss exceeding $5 \%$ of prepregnancy body weight) was considered as a different group from severe NVP and used as an exclusion criterium. The study was approved by Ethics Committee. After giving information about the study, and obtaining written informed consent from the patient and from the parents when the participant was younger than 18 years old, instructions were given to the patients on how to fill out the Rhodes and SF-36 Questionnaires. After routine first trimester examinations and determining gestational age by obstetric ultrasonography, sociodemographic questionnaire and the Rhodes test were filled out by face to face interview. The participants were administered the SF36 with supervision.

NVP was classified according to its severity using the Rhodes Test, as no NVP, mild, moderate and severe NVP. The groups were compared according to SF-36 scores.

\section{Socio-demographic Questionnaire}

A questionnaire that included personal and obstetrical information was completed.

\section{Rhodes Test}

The Rhodes test, developed by Rhodes et al in 1984 , is one of the most commonly used scales for evaluating the presence and severity of NVP $[14,15]$. The test consists of 8 questions, validated for symptoms that occured in the past 12 hours, which combines physical signs (the number and duration of nausea, vomiting, retching and the volume of vomit at any time) with the feelings of the patient caused by the distress of these symptoms. The total score of the test 
ranges from 8-40; a score 8 was considered no NVP, 9-18 mild, 19-32 moderate, and 33-40 severe NVP.

\section{Short Form Health Survey (SF-36)}

The Short Form Health Survey(SF-36) is a 36item, patient-reported survey of patient health. It was developed by the Rand Corporation in 1992 [16]. It is one of the most commonly used scales in evaluating individual patient health status. It is a self-rating scale that can be filled out in a short period of five to ten minutes. One of the most important advantages of the scale is that the positive and negative aspects of health status can be assessed at the same time. It contains 36 questions in eight subscales, which include physical functioning, role limitations due to physical health problems, bodily pain, general health, vitality, social functioning, role limitations due to emotional problems and mental health perceptions. It evaluates the symptoms of the last four weeks [17]. The first four scales are summarized into the physical summary component (PCS) and the last four scales into the mental summary component (MCS). The score for each subscale ranges from $0-100$ and is directly proportional to the QoL; the lower the score the more disability, the higher the score the less disability. The reliability and validity study of the scale in Turkish, was established in 1999 [18]. Determination of the population norms for the Turkish version of SF-36 were made by Demiral et al. [19] in 2006.

\section{Statistical Analysis}

Statistical analyses were performed using SPSS software version 20.0 (SPSS Inc, Chicago, IL). The suitability of the measurements to normal distribution were determined by "Kolmogorov-Smirnov Test" according to sample size $(\mathrm{n}>30)$. Parametric tests were used for normally distributed variables, otherwise analyses were done with non-parametric tests. In the comparison of 3 or more independent groups, "ANOVA" was used as parametric test and "Kruskal-Wallis H" as a non-parametric test. Tukey was used as posthoc test for ANOVA. Categorical variables were analysed with "Chi-Square Test" statistics. "Multivariable linear regression analyses" were used to show independent variables associated with PCS and MCS scores. $P$ values $<0.05$ were considered to be statistically significant.

\section{RESULTS}

\section{Socio-demographic characteristics}

The socio-demographic characteristics of the patients are shown in Table 1. According to the Rhodes Test results, $74.8 \%$ of the patients had NVP; $36.8 \%$ (n $=92)$ had mild, $28.8 \%(\mathrm{n}=72)$ had moderate, and $9.2 \%(n=23)$ had severe symptoms, whereas $25.2 \%$ $(n=63)$ of the patients had no NVP.

Asignificant relationship was found between the severity of NVP and monthly income $(p=0.033)$. Severe NVP was higher in the high income group whereas no NVP, mild and moderate NVP were higher in the median income level groups. A statistically significant relationship was found between the family structure, number of individuals living in the same home and the severity of NVP. Severe NVP was found to be higher in patients living in an extended family $(p=0.027)$ and those sharing the same home with a greater number of people $(p=0.008)$. Willingness of pregnancy was found to be significantly different between the groups ( $p=0.033)$; the severity of NVP was significantly lower in the planned pregnancy group. The severity of NVP was higher in patients who had difficulties in sharing problems with spouse/relatives $(p=0.001)$ and who had discord/uneasiness within the family $(p=0.001)$ (see Table 1).

\section{SF-36 Scores}

Average SF-36 scores of our whole group in the study were somewhat lower than the general Turkish female population as shown in Table 2. As for SF-36, the PCS median score was $45.20(\min 20.70-\max$ 60.90) and the MCS score was 48.85 (min: 20.30max: 61.40) in the whole group. The no NVP group was found to have the highest average PCS and MCS scores. The scores of PCS and MCS decreased progressively with increasing severity of NVP and remained below the average of the general population scores in the moderate and severe NVP groups. Statistically significant differences were found both in PCS and MCS scores between the groups, with the highest scores in the group with no NVP ( $p=0.001$ and $p=0.001$, respectively). A significant decrease in scores was observed with increasing severity of NVP (Table 3).

According to the results of the subscores of SF- 
Table 1. Distribution of socio-demographic characteristics and family features of the groups

\begin{tabular}{|c|c|c|c|c|c|}
\hline \multirow[t]{2}{*}{ Characteristic } & \multicolumn{4}{|c|}{ NVP Degree } & \multirow[t]{2}{*}{$p$ Value } \\
\hline & None & Mild & Moderate & Severe & \\
\hline Age (years), median (min-max) & $18(16-19)$ & $19(15-19)$ & $19(15-19)$ & $19(16-19)$ & 0.885 \\
\hline $\begin{array}{l}\text { Gestational week, median (min- } \\
\text { max) }\end{array}$ & $12(6-20)$ & $12(5-20)$ & $11(6-20)$ & $13(6-20)$ & 0.653 \\
\hline $\begin{array}{l}\text { Number of individuals at home, } \\
\text { median (min-max) }\end{array}$ & $2(2-7)$ & $2(2-9)$ & $2(2-9)$ & $3(2-7)$ & 0.008 \\
\hline $\begin{array}{l}\text { First antepartum care (week), } \\
\text { median (min-max) }\end{array}$ & $7(5-20)$ & $6(5-14)$ & $6(5-20)$ & $7(5-19)$ & 0.883 \\
\hline Gradiva, median (min-max) & $1(0-3)$ & $1(0-3)$ & $1(0-4)$ & $1(1-3)$ & 0.359 \\
\hline Living children, median (min-max) & $0(0-2)$ & $0(0-1)$ & $0(0-2)$ & $0(0-1)$ & 0.683 \\
\hline Educational level, n (\%) & & & & & 0.415 \\
\hline Elementary school/lower & $43(68.3)$ & $52(56.5)$ & $48(66.7)$ & $14(60.9)$ & \\
\hline High school & $20(31.7)$ & $40(43.5)$ & $24(33.3)$ & $9(39.1)$ & \\
\hline Employment status, n (\%) & & & & & 0.415 \\
\hline Employed & $11(17.5)$ & $12(13)$ & $12(16.7)$ & $0(0)$ & \\
\hline Unemployed & $52(82.5)$ & $80(87)$ & $60(83.3)$ & $23(100)$ & \\
\hline Education level of spouse, n (\%) & & & & & 0.553 \\
\hline Elementary school/lower & $28(44.4)$ & $28(30.4)$ & $25(34.7)$ & $9(39.2)$ & \\
\hline High school & $35(55.6)$ & $64(69.6)$ & $47(65.3)$ & $14(60.8)$ & \\
\hline Emploment status of spouse, $n(\%)$ & & & & & 0.530 \\
\hline Employed & $61(96.8)$ & $86(93.5)$ & $68(94.4)$ & $23(100)$ & \\
\hline Unemployed & $2(3.2)$ & $6(6.5)$ & $4(5.6)$ & $0(0.0)$ & \\
\hline Health security, n (\%) & & & & & 0.675 \\
\hline Yes & $59(93.7)$ & $84(91.3)$ & $64(88.9)$ & $22(95.7)$ & \\
\hline No & $4(6.3)$ & $8(8.7)$ & $8(11.1)$ & $1(4.3)$ & \\
\hline Total monthly income, n (\%) & & & & & $\mathbf{0 . 0 3 3}$ \\
\hline$\leq 1300 \mathrm{TL}$ & $17(27)$ & $23(25)$ & $24(23.3)$ & $5(21.7)$ & \\
\hline 1301-3000 TL & $37(58.7)$ & $44(47.8)$ & $27(37.5)$ & $7(3.5)$ & \\
\hline$\geq 3001 \mathrm{TL}$ & $9(14.3)$ & $25(27.2)$ & $21(29.2)$ & $11(47.8)$ & \\
\hline Family structure, n (\%) & & & & & $\mathbf{0 . 0 2 7}$ \\
\hline Nuclear & $51(81)$ & $62(67.4)$ & $50(69.4)$ & $11(47.8)$ & \\
\hline Extended & $12(19)$ & $30(32.6)$ & $22(30.6)$ & $12(52.2)$ & \\
\hline Planned pregnancy, n (\%)) & & & & & $\mathbf{0 . 0 3 3}$ \\
\hline Yes & $54(85.7)$ & $76(82.6)$ & $52(72.2)$ & $14(60.9)$ & \\
\hline No & $9(14.3)$ & $16(17.4)$ & $20(27.8)$ & $9(39.1)$ & \\
\hline Smoking during pregnancy, n (\%) & & & & & 0.590 \\
\hline Yes & $12(19)$ & $18(19.6)$ & $9(12.5)$ & $3(13)$ & \\
\hline No & $51(81)$ & $74(80.4)$ & $63(87.5)$ & $20(87)$ & \\
\hline $\begin{array}{l}\text { Sharing problems with spouse / } \\
\text { relatives, } \mathbf{n}(\%)\end{array}$ & & & & & 0.001 \\
\hline Yes & $62(88.5)$ & $89(96.7)$ & $52(72.2)$ & $13(56.5)$ & \\
\hline No & $1(1.5)$ & $3(3.3)$ & $20(27.8)$ & $10(43.5)$ & \\
\hline $\begin{array}{l}\text { Discord/uneasiness within the } \\
\text { family, n (\%) }\end{array}$ & & & & & 0.001 \\
\hline Yes, always & $14(22.2)$ & $27(29.3)$ & $37(51.4)$ & $23(100)$ & \\
\hline No & $49(77.8)$ & $65(70.7)$ & $35(48.6)$ & $0(0)$ & \\
\hline
\end{tabular}

$\mathrm{NVP}=$ nause and vomiting in pregnancy, $\mathrm{TL}=$ Turkish Liras

36, except for Role physical (RP) and Role emotional (RE) subscores, statistically significant differences were found in physical functioning, bodily pain, general health, vitality, social function and mental health subscores between all groups. A significant decrease in the scores was observed with increasing severity of NVP, with the lowest scores in the severe NVP group and the highest scores in the group with no NVP $(p<0.05)$ (Table 3).

RP and RE subscores were similar between the 
Table 2. Comparison of SF-36 PCS and MCS scores in our study population with SF-36 scores found general Turkish female population

\begin{tabular}{lccc}
\hline PCS & Data & MCS & Data \\
\hline Turkish Female Population & $46.6 \pm 9.9$ & Turkish Female Population & $47.3 \pm 9.8$ \\
Whole Study Group & $44.6 \pm 7.8$ & Whole Study Group & $43.9 \pm 9.5$ \\
No NVP & $49.9 \pm 5.3$ & No NVP & $50.7 \pm 7.3$ \\
Mild NVP & $48.0 \pm 5.7$ & Mild NVP & $46.5 \pm 7.5$ \\
Moderate NVP & $39.2 \pm 5.7$ & Moderate NVP & $38.2 \pm 6.7$ \\
Severe NVP & $33.7 \pm 5.1$ & Severe NVP & $32.5 \pm 9.2$ \\
\hline Data are shown as mean \pm standard deviation, MCS = Mental summary component, NVP = nause and \\
vomiting in pregnancy, PCS = Physical summary component
\end{tabular}

groups with no NVP and mild NVP, whereas they were significantly higher inthe moderate and severe NVP groups, with the lowest scores in the severe NVP group.

Multivariable regression analysis that was done to determine the effects of the variables on PCS and MCS scores showed that the severity of NVP and the number of living children were factors significantly associated with PCS scores, whereas sharing problems with spouse/relatives and severity of NVP were found

Table 3. Mean health related quality of life scores for the groups for each of the domains of the Short Form Health Survey (SF36)

\begin{tabular}{|c|c|c|c|c|c|}
\hline \multirow[t]{2}{*}{ Domain } & \multicolumn{4}{|c|}{ Mean HRQOL scores } & \multirow[t]{2}{*}{$p$ Value } \\
\hline & None & Mild NVP & Moderate NVP & Severe NVP & \\
\hline Physical functioning & $85(50-100)$ & $80(40-100)$ & $40(5-100)$ & $45(0-80)$ & $\begin{array}{c}\mathbf{0 . 0 0 1} \\
\mathrm{D}(1-3,4) \\
(2-3,4)(3-4)\end{array}$ \\
\hline Role physical & $75(0-100)$ & $75(0-100)$ & $25(0-100)$ & $0(0-50)$ & $\begin{array}{c}\mathbf{0 . 0 0 1} \\
\mathrm{D}(1-3,4) \\
(2-3,4)\end{array}$ \\
\hline Bodily pain & $84(32-100)$ & $74(31-100)$ & $52(20-100)$ & $41(0-64)$ & $\begin{array}{c}\mathbf{0 . 0 0 1} \\
\mathrm{D}(1-3,4) \\
(2-3,4)(3-4)\end{array}$ \\
\hline General health & $77(32-97)$ & $62(32-100)$ & $46(17-77)$ & $40(5-65)$ & $\begin{array}{c}\mathbf{0 . 0 0 1} \\
\mathrm{D}(1-2,3,4) \\
(2-3,4)\end{array}$ \\
\hline Vitality & $70(45-100)$ & $60(30-90)$ & $40(10-80)$ & $30(0-75)$ & $\begin{array}{c}\mathbf{0 . 0 0 1} \\
\mathrm{D}(1-2,3,4) \\
(2-3,4)(3-4)\end{array}$ \\
\hline Social function & $87.5(25-100)$ & $75(25-100)$ & $62.5(0-100)$ & $50(0-100)$ & $\begin{array}{c}\mathbf{0 . 0 0 1} \\
\mathrm{D}(1-3,4) \\
(2-3,4)\end{array}$ \\
\hline Role emotional & $66.7(0-100)$ & $66.7(0-100)$ & $33.30(0-100)$ & $0(0-66.7)$ & $\begin{array}{c}\mathbf{0 . 0 0 1} \\
\mathrm{D}(1-3,4) \\
(2-3,4)(3-4)\end{array}$ \\
\hline Mental health & $80(48-100)$ & $72(36-96)$ & $52(20-80)$ & $36(12-92)$ & $\begin{array}{c}\mathbf{0 . 0 0 1} \\
\mathrm{D}(1-2,3,4) \\
(2-3,4)(3-4)\end{array}$ \\
\hline $\begin{array}{l}\text { Physical Summary } \\
\text { Component }\end{array}$ & $49.85 \pm 5.34$ & $47.97 \pm 5.66$ & $39.22 \pm 5.66$ & $33.70 \pm 5.12$ & $\begin{array}{c}\mathbf{0 . 0 0 1} \\
\mathrm{D}(1-3,4) \\
(2-3,4)(3-4)\end{array}$ \\
\hline $\begin{array}{l}\text { Mental Summary } \\
\text { Component }\end{array}$ & $51.3(34-61)$ & $47.1(25-61)$ & $37.7(26-55)$ & $32.7(20-56)$ & $\begin{array}{c}\mathbf{0 . 0 0 1} \\
\mathrm{D}(1-2,3,4) \\
(2-3,4)(3-4)\end{array}$ \\
\hline
\end{tabular}

Data are shown as median (minimum-maximum) or mean \pm standard deviation. $\mathrm{D}=$ Difference , HRQoL $=$ healthrelated quality of life 
Table 4. Multivariable regression analyses showing independent variables associated with PCS score as the dependent variable in studypopulation

\begin{tabular}{|c|c|c|c|c|c|}
\hline Variables & B & Standard Error & $\boldsymbol{\beta}$ & $\mathbf{t}$ & $p$ \\
\hline Constant & 58,454 & 8.547 & & 6.839 & $<0.001$ \\
\hline Age & -0.183 & 0.422 & -0.022 & -0.432 & 0.666 \\
\hline Education & -1.052 & 0.775 & -0.065 & -1.357 & 0.176 \\
\hline Occupation & 0.955 & 1.160 & 0.043 & 0.823 & 0.411 \\
\hline Education of spouse & 1.115 & 0.680 & 0.089 & 1.640 & 0.102 \\
\hline Health security & -1.744 & 1.413 & -0.062 & -1.234 & 0.218 \\
\hline Total income & 0.000 & 0.000 & 0,020 & 0.265 & 0.792 \\
\hline Number of individuals at home & -0.204 & 1.269 & -0.012 & -0.161 & 0.872 \\
\hline Planned pregnancy & -0.449 & 0.918 & -0.024 & -0.489 & 0,625 \\
\hline Number of living children & -1.720 & 0.789 & -0.107 & -2.179 & 0.030 \\
\hline Sharing problems with spouse/relatives & -0.342 & 0.603 & -0.032 & -0.566 & 0.572 \\
\hline Uneasiness within the family & 0.894 & 0.677 & 0.077 & 1.321 & 0.188 \\
\hline Severity of NVP & -5.264 & 0.485 & -0.627 & -10.843 & $<0.001$ \\
\hline
\end{tabular}

$\mathrm{NVP}=$ nause and vomiting in pregnancy, PCS = Physical summary component

Table 5. Multivariable regression analyses showing independent variables associated with MCS score as the dependent variable in study population

\begin{tabular}{lccccc}
\hline Variables & $\mathbf{B}$ & Standard Error & $\boldsymbol{\beta}$ & $\mathbf{t}$ & $\boldsymbol{p}$ \\
\hline Constant & 59.237 & 11.001 & & 5.385 & $<\mathbf{0 . 0 0 1}$ \\
Age & 0.367 & 0.544 & 0.036 & 0.674 & 0.501 \\
Education & -0.231 & 0.998 & -0.012 & -0.232 & 0.817 \\
Occupation & 0.189 & 1.493 & 0.007 & 0.127 & 0.899 \\
Education of spouse & -0.690 & 0.875 & -0.045 & -0.788 & 0.432 \\
Health security & 0.223 & 1.819 & 0.007 & 0.123 & 0.903 \\
Total income & 0.000 & 0.001 & 0.006 & 0.077 & 0.938 \\
Number of individuals at home & -0.164 & 1.634 & -0.008 & -0.101 & 0.920 \\
Planned pregnancy & -2.241 & 1.182 & -0.097 & -1.896 & 0.059 \\
Number of living children & 1.059 & 1.016 & 0.054 & 1.043 & 0.298 \\
Sharing problems with spouse/relatives & -2.848 & 0.777 & -0.217 & -3.667 & $<\mathbf{0 . 0 0 1}$ \\
Uneasiness within the family & -0.857 & 0.871 & -0.061 & -0.983 & 0.326 \\
Severity of NVP & -5.474 & 0.625 & -0.536 & -8.761 & $<\mathbf{0 . 0 0 1}$ \\
\hline MCS & & &
\end{tabular}

$\mathrm{MCS}=$ Mental summary component, NVP = nause and vomiting in pregnancy

to be factors that influenced MCS scores with statistical significance. According to the coefficient $\beta$, the severity of NVP was found to be the most important predictor of both PCS and MCS scores (Tables 4 and 5).

\section{DISCUSSION}

This study demonstrated two important findings. First, both the presence of NVP and its severity had a negative impact on both PCS and MCS, as well as the other subscores of SF-36; with the highest scores in the group with no NVP and a progressive decrease in all scores with increased severity of NVP. Second, based on multivariable regression, the severity of NVP was the most important predictor of HRQoL scores. The number of living children was also found to be associated with poorer PCS scores, and not being able to share problems with spouse/relatives contributed to poorer MCS scores.

NVP is a common medical condition during gestation that can negatively impact the overall wellbeing of pregnant women. Although it is a very common, age old phenomenon, its outcomes in pregnant adolescents has so far received limited attention in the literature. The overall rate of NVP found in our study was $74.8 \%$, which is similar to 
other studies in the literature, with reported rates between $70-80 \%[9,11,20]$.

The cause of NVP is not well-understood and the etiology of this common condition is still unclear, but it is believed that especially women who have not planned their pregnancy are at higher risk for poor maternal psychosocial adaptation and experience severe NVP, similar to our results [21]. Although there are several studies in the literature reporting increased risk of NVP with younger age, increasing gravidity, and housewife occupational status, we did not find any correlation between NVP and these sociodemographic characteristics [22, 23]. Another factor that is considered to have an adverse effect on NVP is inadequate social support $[21,24]$. Similarly, in our study the severity of NVP was higher in patients who had difficulties in sharing problems with spouse/relatives and who had discord/uneasiness within the family. Increased physical and psychological burden on pregnant women living in extended families compared to those living in nuclear families may explain the significant relationship found between the family structure and the increased number of cohabitants living in the same home and the severity of NVP in our study group.

Despite being one of the most enjoyable periods of a woman's life, maternal health can be adversely affected during pregnancy and emotional-physical problems can arise, particulary in adolescents. While much is known about the physiological changes of pregnancy, the affect of these substantial changes on the health status of women during this period has received limited attention [5]. In recent years, studies examining the health status during pregnancy found lower QoL scores in pregnant women, especially in the emotional and physical role subscores [2, 3, 25]. Average SF-36 scores of our whole group in the study were somewhat lower than the general Turkish female population. This result is consistent with the literature and can be explained by the fact that pregnancy alone is a situation that can affect women's HRQoL. In a study done in our country aimed to determine the QoL of pregnant adolescents ( $<20$ years) and pregnant adults (20-29 years), Taşdemir et al. [25] determined lower QoL scores especially in the first trimester of pregnancy. Similarly, Ramirez-Velez [3] reported that limitations in physical function and restrictions in vitality increased over the course of pregnancy and the decline of mental and general health scores in the physical and emotional role subscores was remarkable. In another study aimed to identify normative changes in health status associated with pregnancy, pregnant women had significantly poorer levels of functioning with regard to bodily pain, physical-social functioning and vitality, and also functional limitations than the general population, which also persisted into the puerperal period [4].

Another important aspect related to QoL on which studies have focused in recent years is NVP in pregnancy, which is one of the most common medical conditions characterized by physiological changes, mainly present in the first trimester of pregnancy. In addition to deterioration in physical health, the mental and physical stress caused by nausea and vomiting can lead to depressive feelings and promote a significant negative influence on family, social and occupational functioning of pregnant women [8, 10]. In our study group, the scores of PCS and MCS of mild and moderate NVP groups were similar to or even slightly higher than the general Turkish female population, whereas the scores fell progressively with increasing severity of NVP and remained below the average of the general population in the moderate and severe NVP groups. Similar to our results, in their study Taşdemir et al. [25] found that all QoL scores of pregnant adolescents were significantly lower than pregnant adults and attributed these results to the incomplete physical and mental maturation of the adolescent pregnant women due to the early pregnancy. When subgroup scores were examined, pregnant women who had mild and moderate NVP had significantly higher levels of functioning with regard to physical functioning, role physical, bodily pain and general health, which compose the PCS component. A significant decrease in all scores was observed with increasing severity of NVP. It is possible that the physical changes occurring in pregnancy can alter the ability of pregnant women to perform their usual roles. Many studies have shown that physical functioning reduces during pregnancy $[4$, 26]. In their study, Haas et al. [5] found that the physical functioning mean score, which showed the highest decrease, was reduced from 95.2 before pregnancy to 58.1 during pregnancy. Similarly, in the study of Mckee et al. [27], results of the SF-36 showed the lowest perceived well-being in physical role 
dimensions. In addition to the physical changes occuring during pregnancy, it is possible that the physical load caused by the symptoms of NVP itself also adversely affect life quality scores. In O'Brien and Naber's study [28], in which they aimed to investigate the magnitude of problems that NVP imposes on the lifestyle of pregnant women, all women with NVP reported changes in family, social and occupational functioning. They determined that the lifestyle limitations that NVP causes can have short- and long-term consequences for both the pregnant women and their families [28]. Many pregnant women complain about the difficulty of maintaining their usual life activities and their ability to work as a result of discomfort and weakness caused by NVP. In another study, approximately $50 \%$ of working women stated that their work efficiency was reduced because of NVP and as many as $25 \%$ required time off from work [29]. In our study, the number of living children was found to be another effective factor in the PCS. This finding also supports the importance of physical burden in the HRQoL of pregnant women.

In addition to its effect on physical QoL, NVP had an impact on mental QoL. A significant decrease in all subscores that compose the MCS (vitality, social function, role emotional, mental health) were observed with increasing severity of NVP. These findings show that the problem goes beyond physical symptoms. Consistent with our findings, an American study found that higher NVP scores contributed to lower QoL in the MCS component [8]. This finding was also replicated in another study done by Attard et al. [30], who reported that NVP affected each of the eight health domains and the two summary scales of SF-36. It is possible that the mental stress caused by NVP can lead to depressive feelings and promotes a significant negative influence on the family, social and occupational functioning for pregnant women who have NVP $[8,10]$. In addition, adolescents may have fewer life experiences than adult women, making them less able to cope with the life changes they are going through related to pregnancy, which could be a factor enhancing their mental stress.

Another point to remember is that a significant decrease in the scores was observed with increasing severity of NVP, with the lowest scores in the severe NVP group and the highest scores in the group with no NVP in our study. The consensus of most studies in the literature is that more severe NVP is associated with poorer HRQoL and the degree of limitation is associated with the severity of symptoms, consistent with our findings $[6-8,30]$.

\section{The Limitations of the Study}

Our study has some limitations. As the nature of the study was cross-sectional, the observed relationships may not be causal. As we do not know the health status of women prior to pregnancy, it is hard to say that all the low scores of HRQoL were related to NVP. Since the Rhodes test is a self rating scale, judging the severity of NVP physical symptoms does not address well women's own perception of the severity of their condition. In order to assess the severity of NVP in the most accurate way, patients were asked to answer the questions after thorough consideration, with sufficient time allocated for them to do this. In our study median age of patients is 19 . Thus our study may not be able to provide complete information for the early adolescence period [10-13]. Despite these limitations, our work broadens the understanding of health quality in adolescent pregnant women who have NVP. To our knowledge, this is the first study carried out with adolescent pregnant women in the literature. Larger prospective studies covering both the pre and ante-partum period are needed to clarify the effect of NVP on HRQoL in adolescent pregnants.

\section{CONCLUSION}

We demonstrated that both the presence and severity of NVP have a significant influence on QoL scores in pregnant adolescents. NVP affects both their physical health and psychosocial functioning so as to disrupt their general sense of well-being and day to day life activities. As adolescent pregnant women are already a group at risk, physical care, social and professional support should be provided to increase their QoL levels. Patients with serious NVP should be given psychological support and medical treatment.

\section{Acknowledgements}

We are grateful to all mothers for participating the study and sharing their time. We also thank to Melih Uzunoglu who did the statistical analysis of the study 
and to P. LeMotte who did the English correction of the study.

\section{Ethical approval}

All procedures performed in studies involving human participants were in accordance with the ethical standards of the institutional and/or national research committee and with the 1964 Helsinki declaration and its later amendments or comparable ethical standards.

\section{Informed consent}

Informed consent was obtained from all individual participants included in the study.

\section{Conflict of interest}

The authors disclosed no conflict of interest during the preparation or publication of this manuscript.

\section{Financing}

The authors disclosed that they did not receive any grant during conduction or writing of this study.

\section{REFERENCES}

[1] The WHOQOL Group. The World Health Organization Quality of Life Assessment (WHOQOL): position paper from the World Health Organization. Soc Sci Med 1995;41:1403-9.

[2] Calou CGP, Pinherio AKB, Castro RCMB, de Oliveira MF, de Souza Aquino $\mathrm{P}$, Antezana F. Health related quality of life of pregnant women and associated factors: an integrative review. Health 2014;6:2375-87.

[3] Ramirez-Velez R. Pregnancy and health-related quality of life: A cross sectional study. Colombia Médica 2011;42:476-81.

[4] Otchet F, Carey MS, Adam L. General health and psychological symptom status in pregnancy and the puerperium: what is normal? Obstet Gynecol 1999;94:935-41.

[5] Haas JS, Jackson RA, Fuentes-Afflick E, Stewart AL, Dean ML, Brawarsky $\mathrm{P}$, et al. Changes in the health status of women during and after pregnancy. J Gen Intern Med 2005;20:45-51.

[6] Smith C, Crowther C, Beilby J, Dandeaus J. The impact of nausea and vomiting on women: a burden of early pregnancy. Aust NZ J Obstet Gynaecol 2000;40:397-401.

[7] Lacasse A, Rey E, Ferreira E, Romero R, Goodwin TM. Nausea and vomiting of pregnancy: what about quality of life? BJOG. 2008;115:1484-93.

[8] Munch S, Korst LM, Hernandez GD, Romero R, Goodwin TM. Health-related quality of life in women with nausea and vomiting of pregnancy: the importance of psychosocial context. J Perinatol 2011;31:10-20.

[9] Verberg MF, Gillott DJ, Al-Fardan N, Grudzinskas JG. Hyperemesis gravidarum, a literature review. Hum Reprod Update 2005;11:527-39.

[10] Yilmaz E, Yilmaz Z, Cakmak B, Karsli MF, Gultekin IB, Guneri
Dogan N, et al. Nausea and vomiting in early pregnancy of adolescents: relationship with depressive symptoms. J Pediatr Adolesc Gynecol 2016:29:65-8.

[11] O'Brien B, Naber S. Nausea and vomiting during pregnancy: effects on the quality of women's lives. Birth 1992;19:138-43.

[12] Veenendaal MV, Van Abeelen AF, Painter RC, Van der Post JA, Roseboom TJ. Consequences of hyperemesis gravidarum for offspring: a systematic review and meta-analysis. BJOG 2011;118:1302.

[13] McCarthy FP, Lutomski JE, Greene RA. Hyperemesis gravidarum: current perspectives. Int J Womens Health 2014;6:719-25.

[14] Rhodes V, Watson P, Johnson M. Development of reliable and valid measures of nausea and vomiting. Cancer Nurs 1984;7:33-41.

[15] Koren G, Magee L, Attard C, Kohli M, Atanackovic G, Bishai R, et al. A novel method for the evaluation of the severity of nausea and vomiting of pregnancy. Eur J Obstet Gynecol Reprod Biol 2001;94:316.

[16] Ware JE, Sherbourne CD. The MOS 36-Item Short-Form Health Survey (SF-36). I. Conceptual framework and item selection. Med Care 1992;30:473-83.

[17] Ware JE, Snow KK, Kosinski M, Gandek B. SF-36 Healty Survey: Manual and Interpretation Guide. New England Medical Center, Boston: The Health Institute; 1993.

[18] Kocyigit H, Aydemir O, Fisek G. [Reliability and Validity of Turkish Version of Short Form-36]. İlaç ve Tedavi Dergisi 1999;12:1026. [Article in Turkish]

[19] Demiral Y, Ergor G, Unal B, Semin S, Akvardar Y, Kivircik B, et al. Normative data and discriminative properties of short form 36 (SF36) in Turkish urban population. BMC Public Health 2006;6:247.

[20] Lee NM, Saha S. Nausea and vomiting of pregnancy. Gastroenterol Clin North Am 2011;40:309-34.

[21] Chou FH, Avant KC, Kuo SH, Fetzer SJ. Relationships between nausea and vomiting, perceived stress, social support, pregnancy planning, and psychosocial adaptation in a sample of mothers: a questionnaire survey. Int J Nurs Stud 2008;45:1185-91.

[22] Louik C, Hernandez-Diaz S, Werler MM, Mitchell AA. Nausea and vomiting in pregnancy: maternal characteristics and risk factors. Paediatr Perinat Epidemiol 2006;20:270-8.

[23] Temming L, Franco A, Istwan N, Rhea D, Desch C, Stanziano G, et al. Adverse pregnancy outcomes in women with nausea and vomiting of pregnancy. J Matern Fetal Neonatal Med 2014;27:84-8.

[24] Kramer J, Bowen A, Stewart N, Muharajine N. Nausea and vomiting of pregnancy: prevalance, severity and relation to psychosocial health. MCN Am J Matern Child Nurs 2013;38:21-7.

[25] Taşdemir S, Balci E, Günay O. Comparison of life quality of pregnant adolescents with that of pregnant adults in Turkey. Ups J Med Sci 2010;15:275-81.

[26] Hueston WJ, Kasik-Miller S. Changes in functional health status during normal pregnancy. J Fam Pract 1998; 47:209-12.

[27] Mckee MD, Cunningnam M, Jankowski KR, Zayas L. Health related functional status in pregnancy: relationship to depression and social support in a multi ethnic population. J Obst Gynecol 2001;97:988993.

[28] O'Brien B, Naber S. Nausea and vomiting during pregnancy: effects on the quality of women's lives. Birth 1992;19:138-43.

[29] Vellacott D, Cooke EJA, James CE. Nausea and vomiting in early pregnancy. Int J Gyn Obst 1988;27:57-62.

[30] Attard CL, Kohli MA, Coleman S, Bradley C, Hux M, Atanackovic $\mathrm{G}$, et al. The burden of illness of severe nausea and vomiting of pregnancy in the United States. Am J Obstet Gynecol 2002;186(5 Suppl Understanding):S220-7. 